\section{俩 Heighten Science \\ P U B L I C I T I O N S Corporation ISSN 2573-6191}

\title{
Large perforating Submandibular Stone-A Case Report
}

\author{
Faaiz Alhamdani* \\ Assistant Professor, College of Dentistry, Ibn Sina University, Baghdad, Iraq
}

*Address for Correspondence: Dr. Faaiz Alhamdani, Assistant Professor, College of Dentistry, Ibn Sina University, Baghdad, Iraq, Email: faaiz@ibnsina.edu.iq

Submitted: 23 January 2018 Approved: 08 February 2018 Published: 09 February 2018

Copyright: @ 2018 Alhamdani F. This is an open access article distributed under the Creative Commons Attribution License, which permits unrestricted use, distribution, and reproduction in any medium, provided the original work is properly cited.

\section{Introduction}

Salivary stone (sialothiasis) is a calcifying concentration within the ductal system of salivary gland [1]. The majority of salivary calculi occur in the submandibular gland duct because of its length, upward course and the thicker mucus [2].

Submandibular salivary stone is a common cause for recurrent submandibular gland swellings [3]. Recurrent obstruction of salivary flow is the main cause for salivary gland swellings, which makes salivary gland removal in some of these cases inevitable, despite the considerable advances in salivary gland calculi management [46]. Large salivary stones (>10 mm) are relatively uncommon [7-9]. Reviews of cases of giant salivary stone were attempted by different authors $[7,10,11]$. However, the review done by [12], was the most comprehensive one. They reported 90 cases of giant salivary stones between 1942 and 2014. Apart from 8 cases included in their review, all the reported stones were between $30-65 \mathrm{~mm}$ in size.

Submandibular salivary gland stones perforating the floor of the mouth, reported in the literature, are even less common. In the last decade 7 cases have been described. The reported cases with perforating submandibular stones were large $(\geq 22 \mathrm{~mm})$. Table 1 summarises the features of the reported cases.

\section{Case Report}

Thirty five old male attended Training Dental Centre/ Baghdad complaining from moderately severe pain and a swelling in the left submandibular area. The pain started 10 days earlier. At that time the patient was already under Amoxicillin $500 \mathrm{mg} 8$ hourly for throat infection. At the beginning the pain was mild and it was triggered by eating and wide mouth opening. After 6 days the pain became more intense, but the swelling did not increase in size. At the tenth day, the day he attended the clinic the pain became intolerable, as described by the patient. The patient took Diclofenac powder oral solution $50 \mathrm{mg}$ for pain control.

History taking revealed that in 2010 the patient complained from pain and swelling in the left submandibular gland. He went to Germany where the submandibular stone

Table 1: Characteristics of reported cases with perforating salivary stones in the last decade.

\begin{tabular}{|c|c|c|c|c|c|c|}
\hline No. Of case & Author(s) & Year & Gender & Age & position & Size $(\mathbf{m m})$ \\
\hline 1 & (Parkar et al.) & 2011 & Female & 84 & submandibular & $9 \times 5 \mathrm{~mm}$ \\
\hline 2 & (Singhal et al.) & 2012 & $\begin{array}{c}\text { Male } \\
\text { Male }\end{array}$ & 51 & $\begin{array}{c}\text { Submandibular } \\
\text { submandibular }\end{array}$ & $\begin{array}{c}18 \mathrm{~mm} \\
21 \mathrm{~mm}\end{array}$ \\
\hline 1 & (Nemade et al.) & 2013 & Male & 46 & Submandibular & $16 \times 10 \mathrm{~mm}$ \\
\hline 1 & (Hegde et al.) & 2014 & Male & 55 & Submandibular & $40 \mathrm{~mm}$ \\
\hline 1 & (Kurtoğlu et al.) & 2015 & Female & 52 & submandibular & $25 \times 8 \times 6 \mathrm{~mm}$ \\
\hline 1 & (Saluja et al.) & 2016 & Male & 65 & submandibular & $22 \times 14 \mathrm{~mm}$ \\
\hline
\end{tabular}


was removed using sialoscopic approach. The patient had what he described as similar symptoms to what he was experiencing when he attended the dental centre. He was prescribed Cefadroxil 500mg and the symptoms disappeared.

The patient did not ask for medical attention earlier despite he suspected a submandibular stone presence in left side, because he had previous encounter of similar situation, but when he passed his finger over the posterior sublingual area he felt part of the stone out of the duct. The aggravated pain and swelling with the feeling of a stone inside the mouth let the patient to ask for medical attention. On examination the patient had a tens painful submandibular swelling. Intra oral examination showed part of extruding submandibular stone from the posterior part of Wharton's duct medial to lower second molar tooth (Figure 1). This protruding part caused traumatic ulcer to the adjacent part of the tongue (Figure 2). Patient's permission was taken to photograph the case and he consented to report the case at the end of the visit.

Upon the attempt to remove the stone, the operator lifted the submandibular gland upward by applying upward pressure on submandibular region to facilitated manipulation of the intra-operative site. This lifting attempt resulted in complete removal of the stone out of the duct. The length of the oval shaped stone was measured (18 $\mathrm{mm}$ ) figure 3. Milking of the gland was performed to release the engorged saliva in the obstructed salivary duct. The swelling decreased and the pain was relieved. The site was inspected after the stone exit. As the site was too far to attempt any closure for the wound, the surgeon decided to let the perforation site to heal with secondary intention.

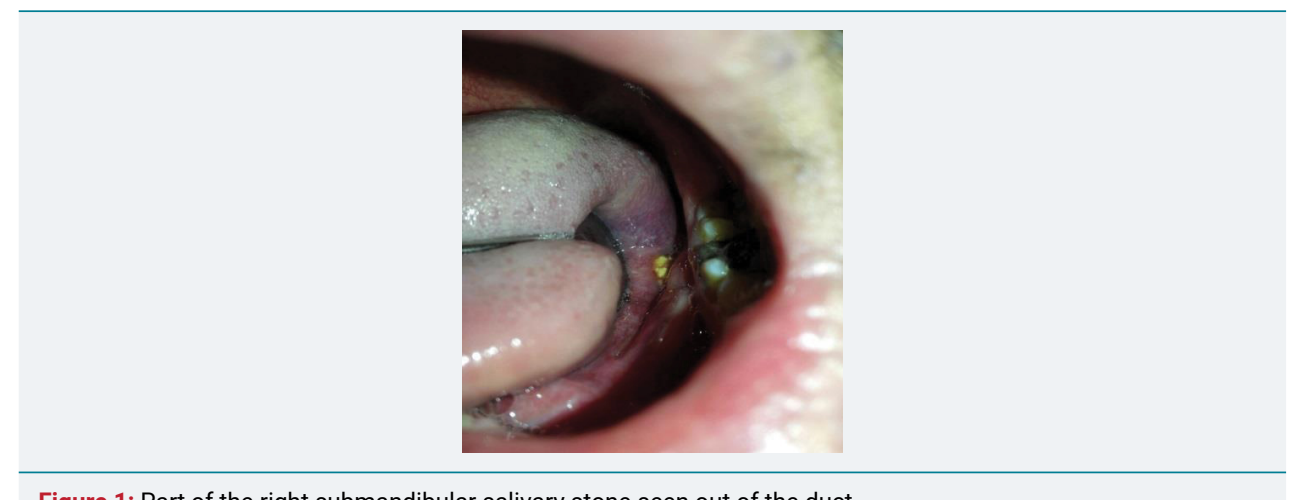

Figure 1: Part of the right submandibular salivary stone seen out of the duct.

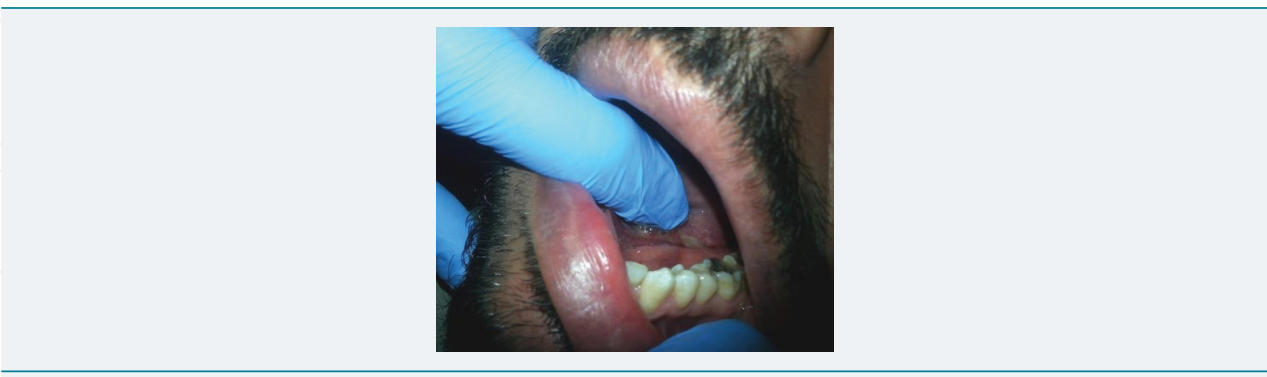

Figure 2: Ulceration of the tongue caused by the rough surface of the exposed part of the salivary stone.

Figure 3: Size of the removed salivary stone. 
Doxicyclin 100 mg single q.d. was described with the continuation of Diclofenac powder t.i.d. Antiseptic mouth wash $\left(\right.$ Silca $\left.^{\circledR}\right)$ b.i.d. was prescribed for one week allowing the spontaneous closure of the duct. Three weeks later the patient visited the centre for follow up. The wound healed reasonably with no further complaint reported by the patient (Figure 4). The patient was advised to report to the surgeon, if the condition recurs.

\section{Discussion}

Salivary stones composed of mineralised nucleus surrounded by organic and inorganic substances arranged as concentric laminated layers. The organic constituents include collagen, glycoproteins, amino acids and carbohydrates, whereas the major inorganic constituents are hydroxyapatite, carbonate apatite, whitlockite and brushite [13].

Salivary stones larger than $15 \mathrm{~mm}$ in one dimension are classified as giant stones $[14,15]$. Such giant stones may reach to considerable size (4 to $5 \mathrm{~cm}$ ) without causing perforation of the floor. Nevertheless, it is possible that stone enlargement to considerable sizes with failure of the duct to accommodate to such enlargement might result in perforation or opening of "new ductal course" or fistula with subsequent infection. Salerno et al, conducted a 12 year review on submandibular fistulae. They found that all submandibular glands fistulae were detected in the posterior part of floor of the mouth and 5 out of 6 fistulae were associated with salivary glands infection [16].

Perforating salivary stones are described in literature with different terms: perforating stone (sialolith), self-exfoliating stone or stone related sialo-oral fistula. The described perforating stones over the last decade mainly affected old adult $\geq 40$ years [12]. Stated that giant salivary stones are more commonly found in fifth to seventh decade of life unlike the normal stones, which affect patients in their third to sixth decade of life.

There are no specific criteria for perforating salivary stones in terms of their size or stone position along the submandibular duct. This makes it difficult to provide explanation for incidence of perforation. However, most of the reported cases involved old adults. This might suggest that age factor seems to play a role.

The submandibular stone presented in this case occurred in relatively younger age (35 years). It has been suggested that acute inflammation of submandibular gland with stones may result in posterior perforation of the floor of mouth [1]. However, it is possible that the stricture of the duct due to previous stone formation [12], and the rough surface of the current stone might play a contributing factor and enforce the stone toward the relatively less resistant duct wall and the posterior floor of the oral cavity.

Surgical repair after stone removal is performed either by closure of the mucosal wound [2], or suturing the ductal lining to the mucosa creating new duct opening (sialodechoplasty) $[17,18]$. Proximal stones posterior to first molar teeth are, however, difficult to approach and hazardous to the lingual nerve [10]. In this case it was difficult

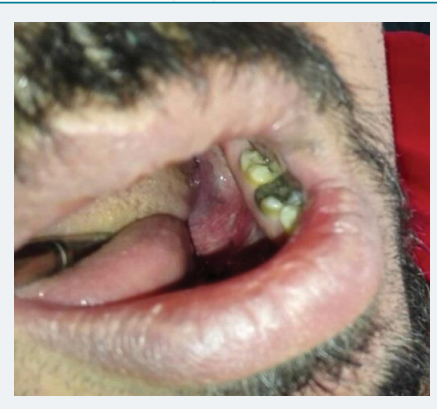

Figure 4: The perforation site 3 weeks after salivary stone removal. 
to approach the site of perforation for surgical repair. Luckily, lifting of the involved submandibular gland resulted in exfoliation of the stone without the need for surgery. Leaving the perforation site resulted in healing of the wound by secondary intention.

\section{Conclusion}

This case report described the incidence of perforating salivary stone at Wharton's duct previously involved with another stone formation. Healing of posterior floor perforation caused salivary stone by secondary intention was uneventful.

\section{Reference}

1. El Deeb $M$, Holte N, Gorlin RJ. Submandibular salivary gland sialoliths perforated through the oral floor. Oral Surg Oral Med Oral Pathol. 1981; 51: 134-139. Ref.: https://goo.gl/c2Y4pa

2. Mitchell DA. Editor. Salivary Glands. Boca Raton: CRC Press. 2015.

3. Parkar MI, Vora MM, Bhanushali DH. A Large Sialolith Perforating the Wharton's Duct: Review of Literature and a Case Report. J Maxillofac Oral Surg. 2012; 11: 477-482. Ref.: https://goo.gl/9L5BGF

4. Jadu FM, Jan AM. A meta-analysis of the efficacy and safety of managing parotid and submandibular sialoliths using sialendoscopy assisted surgery. Saudi Med J. 2014; 35: 1188-1194. Ref.: https://goo.gl/AP4Upc

5. McGurk M, Escudier MP, Brown JE. Modern management of salivary calculi. Br J Surg. 2005; 92 107-112. Ref.: https://goo.gl/S8Tpxq

6. Mehanna H, McQueen A, Robinson M, Paleri V. Salivary gland swellings. BMJ. 2012; 345. Ref.: https://goo.gl/mZh7NL

7. Leite TC, Blei V, Oliveira DPd, Robaina TF, Janini MER, et al. Giant Asymptomatic Sialolithiasis. Int J Oral-Med Sci. 2011; 10: 175-178. Ref.: https://goo.gl/gafHvi

8. Patil Ma, Patil SM. An Unusual Large Submandibular Salivary Gland Calculus- A case Report. Indian Journal of Applied Research. 2014; 4: 328-329.

9. Siddiqui SJ. Sialolithiasis: an unusually large submandibular salivary stone. Br Dent J. 2002; 193: 89-91. Ref.: https://goo.gl/FKcZ6r

10. Babu KL, Jain MK. Giant Submandibular Sialolith: A Case Report and Review of Literature. International Journal of Head and Neck Surgery. 2011; 2: 154-157.

11. Saluja H, Kasat VO, Mahindra U. Giant Sialolith in the Wharton's duct causing sialo-oral fistula: A case report and review of literature. Journal of Orofacial Sciences. 2016; 4: 137-142. Ref.:Ref.: https://goo.gl/t8ko8E

12. Silva PF, Hage CDA, Pontes FSC, Goncalves FLN, Queiroz APD. Giant Sialoliths: Literature Review and Report of One Case with Mouth Floor Perforation. Journal of Surgical and Clinical Dentistry. 2015; 5: 5-11. Ref.: https://goo.gl/p2cs9F

13. Kraaij S, Karagozoglu KH, Forouzanfar T, Veerman EC, Brand HS. Salivary stones: symptoms, aetiology, biochemical composition and treatment. Br Dent J. 2014; 217: 23. Ref.: https://goo.gl/uSSGYW

14. Fowell C, MacBean A. Giant salivary calculi of the submandibular gland. J Surg Case Rep. 2012; 2012: 6. Ref.: https://goo.gl/VBB4GF

15. Gupta A, Rattan D, Gupta R. Giant sialoliths of submandibular gland duct: Report of two cases with unusual shape. Contemp Clin Dent. 2013; 4: 78-80. Ref.: https://goo.gl/C5eLJW

16. Salerno S, Giordano J, Rusignuolo R, Tona GL, Casto AL. Unusual Sponaneous Salivary Fistula: A retrospective Rview of the Last 12 Years. Acta Medica Mediterranea. 2014; 30: 991-994. Ref.: https://goo.gl/GRXMBi

17. Miloro M, editor. Diagnosis and Management of Salivary Gland Disorders. SI. Louis Missouri: MOSBY. 2008.

18. Parkar MI, Vora MM, Bhanushali DH. A Large Sialolith Perforating the Wharton's Duct: Review of Literature and a Case Report. J Maxillofac Oral Surg. 2011; 11: 477-482. Ref.: https://goo.gl/9L5BGF 